\title{
Potential role of BCL2 in the recurrence of uterine smooth muscle tumors of uncertain malignant potential
}

\author{
DONATELLA CONCONI ${ }^{1}$, VALENTINA CHIAPPA ${ }^{2}$, PATRIZIA PEREGO ${ }^{3}$, SERENA REDAELLI $^{1}$, GIORGIO BOVO $^{3}$, \\ MARIALUISA LAVITRANO ${ }^{1}$, RODOLFO MILANI ${ }^{1,2}$, LEDA DALPRÀ $^{1,4}$ and ANDREA ALBERTO LISSONI ${ }^{1,2}$ \\ ${ }^{1}$ School of Medicine and Surgery, University of Milano-Bicocca, I-20900 Monza; ${ }^{2}$ Department of Obstetrics and Gynecology, \\ Units of ${ }^{3}$ Pathology and ${ }^{4}$ Medical Genetics, San Gerardo Hospital, I-20900 Monza, Italy
}

Received February 23, 2016; Accepted March 30, 2016

DOI: $10.3892 /$ or.2016.5274

\begin{abstract}
Uterine smooth muscle tumors are the most common female genital tract neoplasms. While leiomyosarcoma has been studied at length, smooth muscle tumors of uncertain malignant potential (STUMPs) still have ambiguous and unresolved issues, with a risk of relapse and evolution largely undefined. We performed an array comparative genomic hybridization analysis on a primitive STUMP and its local recurrence, histologically diagnosed as undifferentiated sarcoma. To the best of our knowledge, our report is the first genomic study on primitive STUMPs and the different relapsed tumors. The results showed few copy number alterations shared between both samples and the high heterogeneity in the STUMP was apparently lost in the sarcoma. Surprisingly the STUMP presented an amplification of the BCL2 gene, not observed in the relapsed tumor. Additionally, fluorescence in situ hybridization and immunohistochemical staining were performed to confirm BCL2 amplification and expression in these samples and in two other cases of primitive STUMPs and their corresponding relapsed tumors. The presence of $B C L 2$ in multiple copies and expression in the two primitive STUMPs and two relapsed tumors was confirmed. The marked amplification of the BCL2 gene present in the primitive STUMP and the multiple copies also observed in other cases, suggest its potential role as a marker of STUMP malignant potential and recurrence.
\end{abstract}

\section{Introduction}

The smooth muscle is, as all other human tissues, subject to tumor transformation. Their diffused localization in the body allows subdivision of these tumors into groups and subgroups

Correspondence to: Dr Andrea Alberto Lissoni or Dr Donatella Conconi, School of Medicine and Surgery, University of MilanoBicocca, via Cadore 48, I-20900 Monza, Italy

E-mail: andreaalberto.lissoni@unimib.it

E-mail: donatella.conconi@unimib.it

Key words: BCL2, STUMP, recurrence, copy number alterations, amplification corresponding to their anatomical regions. In particular, regarding the female genital tract, the uterine smooth muscle is a site with frequent onset of three main groups of tumors: leiomyoma (benign), smooth muscle tumors of uncertain malignant potential (STUMPs) and leiomyosarcoma (malignant).

Leiomyosarcoma is a rare tumor, accounting for only about $1.3 \%$ of all uterine malignancies and it usually exhibits an extremely malignant clinical course. The risk of local/metastatic recurrence is high and the reported 5-year survival rate is only $12-25 \%(1)$.

STUMPs are a rare class of uterine neoplasms still partially unknown and while an anatomopathological classification has been defined, their risk of relapse and progression into leiomyosarcoma is largely undefined. Therefore, counseling and follow-up strategies for patient with this disease remain undetermined. STUMPs are usually clinically benign but in some cases, recurrence can occur many years following surgery (both conservative and aggressive) (2).

In order to improve our knowledge of the prognostic factors of STUMPs, we evaluated, from a clinical, pathological and genetic point of view, three patients with recurrences who required diagnosis and treatment at the Gynecologic Oncology Clinic at San Gerardo Hospital in Monza.

The first case was a woman who showed a uterine primitive STUMP and a local recurrence, histologically diagnosed as undifferentiated sarcoma. The second patient had a primitive STUMP followed by a second STUMP. The third case showed a primitive STUMP and a recurrence diagnosed as leiomyosarcoma.

In this study, we report for the first time to the best of our knowledge a genomic study on primitive STUMP and its relapsed tumor. Additionally, fluorescence in situ hybridization and immunohistochemical staining were performed on these samples and on two other cases of primitive STUMPs and their corresponding relapsed tumors.

\section{Patients and methods}

Case 1. Case 1 was a 46-year-old lady, referred to our clinic after laparoscopic operative myomectomy for a 7-cm myoma in February 2007, who underwent a hysterectomy, due to a pathological diagnosis of STUMP, confirmed by pathological review of the specimen. 
In December 2008 the patient presented femoral vein thrombosis and hydronephrosis due to a mixed (mainly solid) 9-cm right pelvic mass involving the iliac vessels; lung metastases were diagnosed with a CT-scan. A few days later she developed haemoperitoneum.

In the emergency room a laparotomy was performed, with a partial tumorectomy and ileocholic resection (according to Hartmann's procedure). A diagnosis of high malignant leiomyosarcoma was determined by the pathologist.

The patient received four courses of chemotherapy with doxorubicin $\left(75 \mathrm{mg} / \mathrm{m}^{2}\right)$ and ifosfamide $\left(10 \mathrm{~g} / \mathrm{m}^{2}\right)$ with progressive disease after initial partial response. A second line of chemotherapy with gemcitabine and docetaxel was therefore performed, with no results.

The patient succumbed to the disease 12 months after the diagnosis of recurrence and 34 months from the initial diagnosis of STUMP (December 2009).

Case 2. Case 2 had a total abdominal hysterectomy and bilateral salpingo-oophorectomy at 47 years of age (1999) with a preoperative diagnosis of a $5-\mathrm{cm}$ myoma. The pathological diagnosis was STUMP, confirmed by a pathological review of the specimen.

Seven years later (June 2006), the patient developed a retroperitoneal (right external iliac - obturatory) mass of $6 \times 4 \mathrm{~cm}$. Laparotomic tumorectomy was performed. Following a pathological diagnosis of STUMP with estrogen (ER) and progesterone $(\mathrm{PgR})$ positivity at $70 \%$, hormonal treatment with megestrol acetate $160 \mathrm{mg}$ daily was recommended.

In August 2010, the patient developed a new right pelvic recurrence of STUMP and was treated with surgery and external beam radiotherapy (45 Gy). The patient is alive and disease-free.

Case 3. Case 3 was admitted to our hospital in October 2002, who at 41 years of age underwent multiple myomectomy (5-cm myomas) with a postoperative diagnosis of STUMP The follow-up was uneventful until May 2006 (43 months of DFI), when a large, rapidly growing myoma of $7.5 \mathrm{~cm}$ in diameter was diagnosed. A total hysterectomy and bilateral salpingo-oophorectomy were performed, with a diagnosis of high-grade leiomyosarcoma. A PET/CT scan was negative for distant metastases however four courses of adjuvant postoperative chemotherapy with doxorubicin and ifosfamide were administered. In December 2007, a large abdominal recurrence with liver metastases was diagnosed. Three further courses of chemotherapy with docetaxel, trabectedin, POMB-ACE and hormonal treatment did little in controlling the disease. The patient succumbed 86 months after the initial diagnosis of STUMP and 43 months after recurrence (December 2009). Written informed consent to the use of biological specimen was obtained from all patients at the time of surgery.

Array comparative genomic hybridization analysis (array-CGH). Genomic DNA extraction from formalin-fixed paraffin-embedded (FFPE) sections, sample preparation, slide hybridization and analysis were performed using a SurePrint G3 Human CGH Microarray kit 8x60K (Agilent Technologies, Inc., Santa Clara, CA, USA) following the manufacturer's instructions. The arrays were scanned at $2-\mu \mathrm{m}$ resolution using an Agilent microarray scanner and analyzed using Feature
Table I. Shared CNAs between STUMP (upper value) and sarcoma (bottom value).

\begin{tabular}{clcl}
\hline Chr & Cytoband & AvgCGHLR & \multicolumn{1}{c}{ Gene names } \\
\hline 1 & $\mathrm{p} 22.2-\mathrm{p} 22.1$ & 3.37 & TGFBR3 \\
& & 3.39 & \\
2 & $\mathrm{q} 32.2$ & 3.25 & COL5A2 \\
& & 2.95 & \\
12 & $\mathrm{q} 24.11$ & 2.82 & SART3, ISCU, TMEM119, \\
& & 2 & SELPLG, CORO1C, SSH1 \\
13 & $\mathrm{q} 32.1$ & 2.51 & UGCGL2 \\
& & 1.51 & \\
19 & $\mathrm{q} 13.43$ & 3.64 & CHMP2A, UBE2M, \\
& & 1.98 & LOC100131691, MZF1 \\
21 & $\mathrm{q} 22.3$ & 3.94 & C2CD2, ZNF295 \\
& & 2.02 & \\
22 & $\mathrm{q} 12.1$ & 2.26 & PITPNB \\
& & 2.21 & \\
$\mathrm{X}$ & $\mathrm{q} 28$ & 1.46 & ARHGAP4, ARD1A, \\
& & 1.35 & RENBP, HCFC1
\end{tabular}

TGFBR3: decreased expression of this receptor has been observed in various cancers (5-7). COL5A2: colorectal carcinogenesis is associated with stromal expression of COL11A1 and COL5A2 (20). SART3: an RNA-binding nuclear protein that is a tumor-rejection antigen. This antigen possesses tumor epitopes capable of inducing HLA-A24-restricted and tumor-specific cytotoxic $\mathrm{T}$ lymphocytes in cancer patients and may be useful for specific immunotherapy (www.genecards.org). CORO1C: silencing of CORO1C gene expression inhibited cancer cell proliferation, migration and invasion (10). SSH1: plays a role in cancer cell motility and invasion. Amplification reported in testicular germ cell tumor $(21,22)$. CHMP2A: diseases associated include osteosarcoma, and adenocarcinoma (www.genecards.org). MZF1: significantly induces tumor formation and liver metastasis, furthermore, MZF1 expression is positively correlated with Axl expression in resected colorectal cancer. Diseases associated also include bladder TCC (www.genecards.org) (23).

Extraction v10.10 and Agilent Genomic Workbench v.6.0 software (Agilent Technologies). The aberration detection method-2 (ADM-2) algorithm was used to compute and assist in the identification of aberrations for a given sample. Significant chromosomal aberrations were determined using the algorithm ADM-2 (threshold, 5; absolute minimum average $\log 2$ ratio, 0.50 ; with at least three or more consecutive probe sets).

Fluorescence in situ hybridization (FISH) analysis. Fluorescence in situ hybridization analysis of FFPE tissue sections was performed using an $I G H / B C L 2$ translocation, dual fusion probe (Cytocell, Cambridge, UK), an AneuVysion Multicolor DNA Probe kit (Abbott Molecular) and a UroVysion bladder cancer kit (Vysis) according to the manufacturer's instructions. All digital images were captured using a Leitz microscope (Leica DM 5000B) equipped with a charge-coupled device (CCD) camera and analyzed by means of Chromowin software (Tesi Imaging, Milano, Italy).

Immunohistochemistry. Immunohistochemical staining was performed on FFPE (4\% formalin) sections of $1-\mu \mathrm{m}$ 

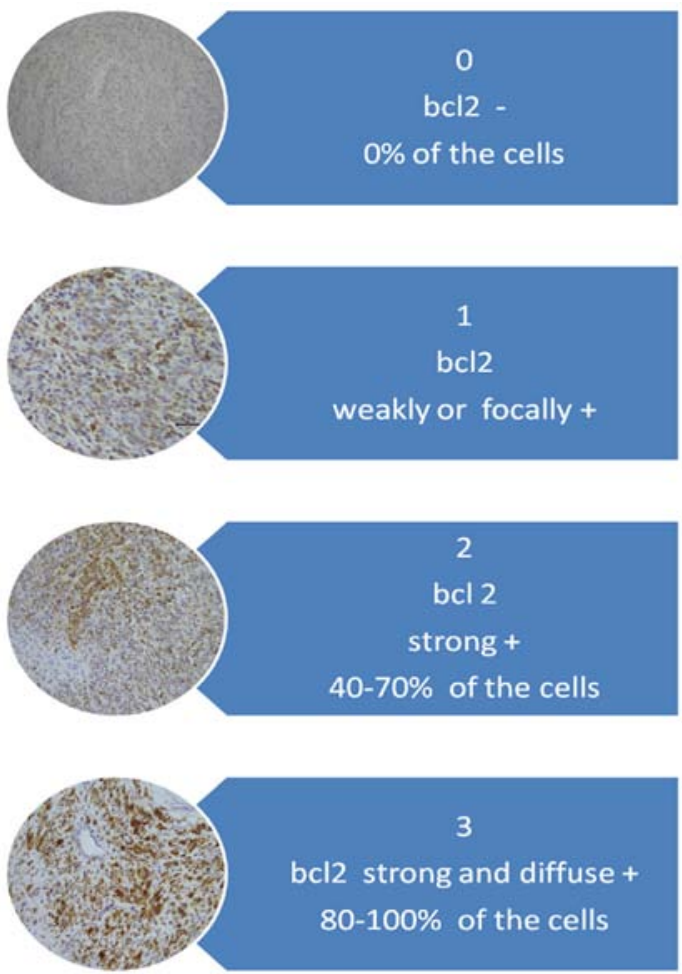

Figure 1. Evaluation system for the BCL2 protein. thickness. The entire pre-treatment process of deparaffinization, rehydration and epitope retrieval was performed using PT LINK (Dako). Then the sections were placed into the Autostainer Link 48 with the EnVision FLEX visualization system. The evaluated markers were ER, PgR, p16, p53 and Ki67 for mitotic activity.

For interpretation of immunohistochemical staining, the system proposed by Ip et al (3) was adopted. For the Bcl-2 protein evaluation system, a scale of staining intensity and localization is described in Fig. 1.

\section{Results}

Array-CGH results. Array-CGH analysis was performed on a primitive STUMP and on the relapsed undifferentiated sarcoma (Fig. 2A). The STUMP showed a higher number of copy number alterations (CNAs) compared to the sarcoma (365 vs. 28); gains represent a totality of the sarcoma variations and the majority of STUMP (342/365). Among the losses, 18 were complete losses (homozygosity), three were heterozygous losses and two losses were mosaic and apparently randomly distributed.

The two tumors shared only eight CNAs containing genes associated with cancer (Table I). For example, CNA in the 1p22.2-p22.1 included the transforming growth
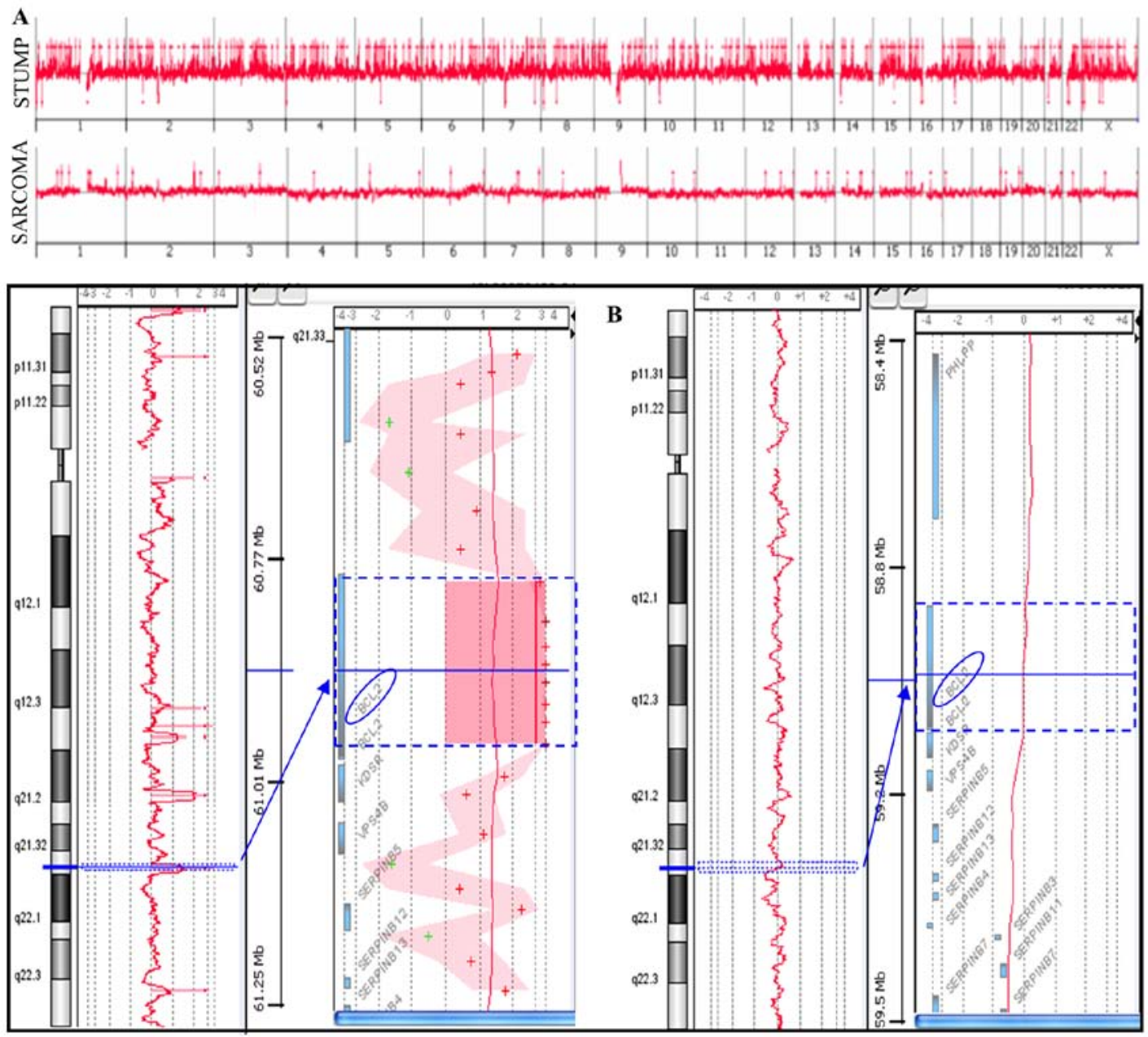

Figure 2. (A) Genomic profiles of both a STUMP and the undifferentiated sarcoma. (B) Chromosome 18 with BCL2 amplification in STUMP (left) and the absence of gain in the undifferentiated sarcoma (right). STUMP, smooth muscle tumors of uncertain malignant potential. 

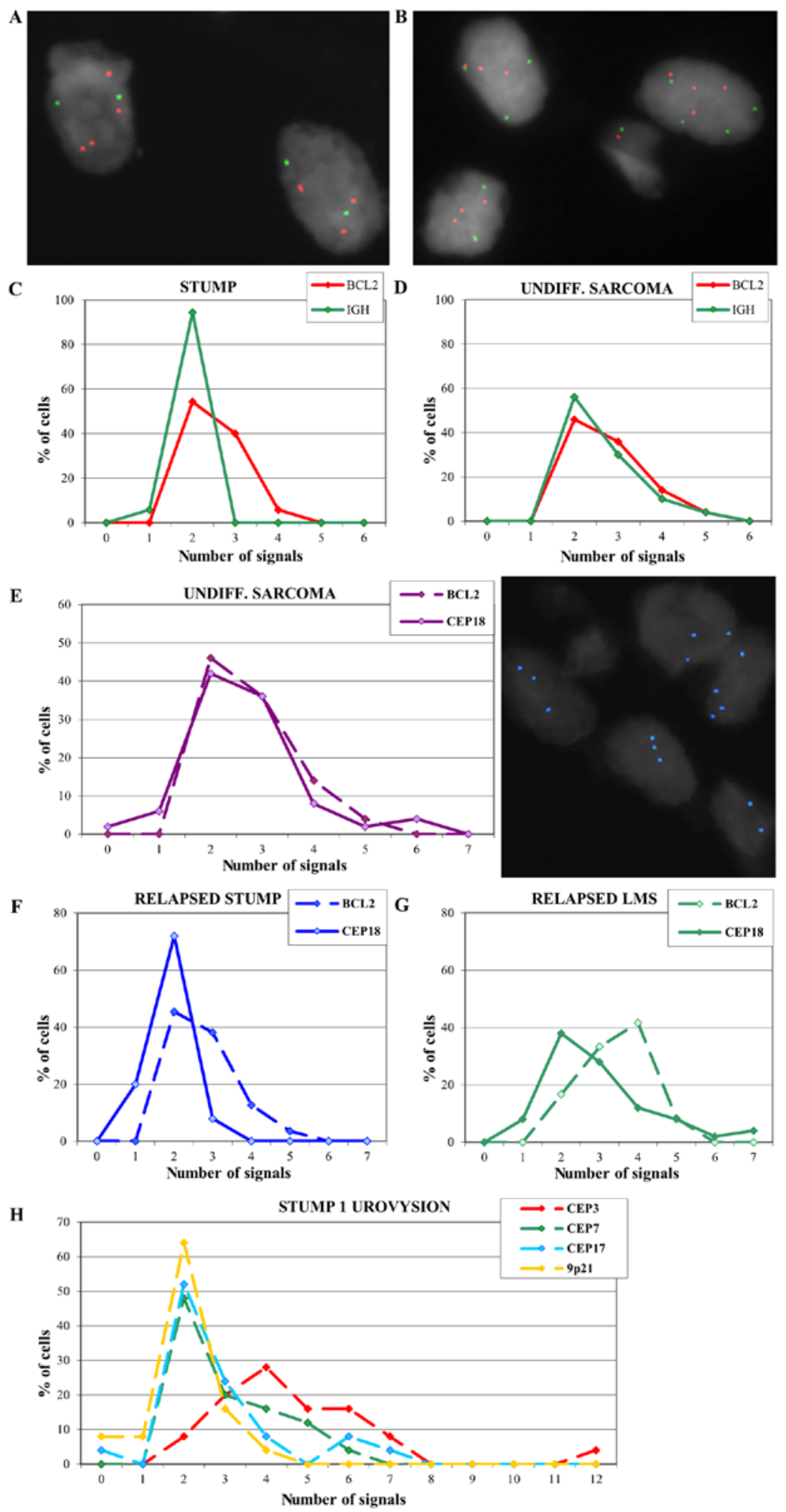

Figure 3. (A) Nuclei after FISH with an IGH/BCL2 probe in primitive STUMP. (B) Nuclei after FISH with an IGH/BCL2 probe in relapsed sarcoma. (C) Distribution of BCL2 and IGH signals in primitive STUMP. (D) Distribution of BCL2 and IGH signals in relapsed sarcoma. (E) Distribution of BCL2 and CEP18 probe signals in undifferentiated sarcoma (left) and nuclei with polysomy of chromosome 18 (right). (F) Distribution of BCL2 and CEP18 probe signals in case 2. (G) Distribution of BCL2 and CEP18 probe signals in case 3. (H) Distribution of UroVysion probe signals on primitive STUMP. STUMP, smooth muscle tumors of uncertain malignant potential.

factor $\beta$ type III receptor (TGFBR3) gene, whose expression has been observed in various types of cancers.

To identify possible functional groups highly represented in the genes included in the shared CNAs, a gene ontology analysis was performed using the GOstat software, but no GO term was statistically significant, probably due to the small number of shared genes.

Among the unshared CNAs, a $B C L 2$ gene amplification (4.7 $\log 2$ ratio, 52 copy number) emerged. $B C L 2$ is an anti-apoptotic gene that prevents the normal course of 
Table II. Histological diagnosis and immunocharacterization of the samples.

\begin{tabular}{|c|c|c|c|c|c|c|c|c|c|c|}
\hline $\begin{array}{l}\text { Case } \\
\text { no. }\end{array}$ & Lesion & $\begin{array}{l}\text { Year of } \\
\text { surgery }\end{array}$ & $\begin{array}{l}\text { Mitoses/ } \\
10 \mathrm{HPF}\end{array}$ & Ki67 & Markers & Estrogen & Progesterone & p16 & $\mathrm{p} 53$ & $\mathrm{Bcl} 2$ \\
\hline \multirow[t]{2}{*}{1} & STUMP & 2008 & $4-5$ & $<1 \%$ & $\operatorname{Actin}^{++}$ & Neg. & Neg. & Neg. & Neg. & 1 \\
\hline & $\begin{array}{l}\text { Undifferent. } \\
\text { Sarcoma }\end{array}$ & 2009 & 14 & $20 \%$ & $\begin{array}{l}\text { Vimentin } \\
\text { desmin } \\
\text { ded }^{+-}, \text {calponin }^{+}, \text {actin }^{+/-}, \\
\text {calretinin } \\
\text {, }\end{array}$ & Neg. & Neg. & Neg. & $3+$ & Neg. \\
\hline \multirow[t]{2}{*}{2} & STUMP & 1999 & NA & NA & NA & NA & NA & NA & NA & NA \\
\hline & STUMP & 2006 & 2 & $3 \%$ & $\operatorname{Actin}^{+++}, \operatorname{desmin}^{+++}, \mathrm{CD}^{-}$ & $90 \%$ & $70 \%$ & Neg. & $2+$ & 1 \\
\hline \multirow[t]{2}{*}{3} & STUMP & 2002 & 3 & $<5 \%$ & $\begin{array}{l}\text { Actin }^{++}, \text {desmin } \\
\text { CD } 10^{++} \text {focal }\end{array}$ & $30 \%$ & $60 \%$ & Neg. & $2+$ & 2 \\
\hline & LMS & 2006 & 15 & $40 \%$ & $\operatorname{Actin}^{+}, \operatorname{desmin}^{+++}, \mathrm{CD} 10^{+}$ & Neg. & $60 \%$ & Neg. & Neg. & 2 \\
\hline
\end{tabular}

NA, not available; STUMP, smooth muscle tumors of uncertain malignant potential; LMS, leiomyosarcoma.
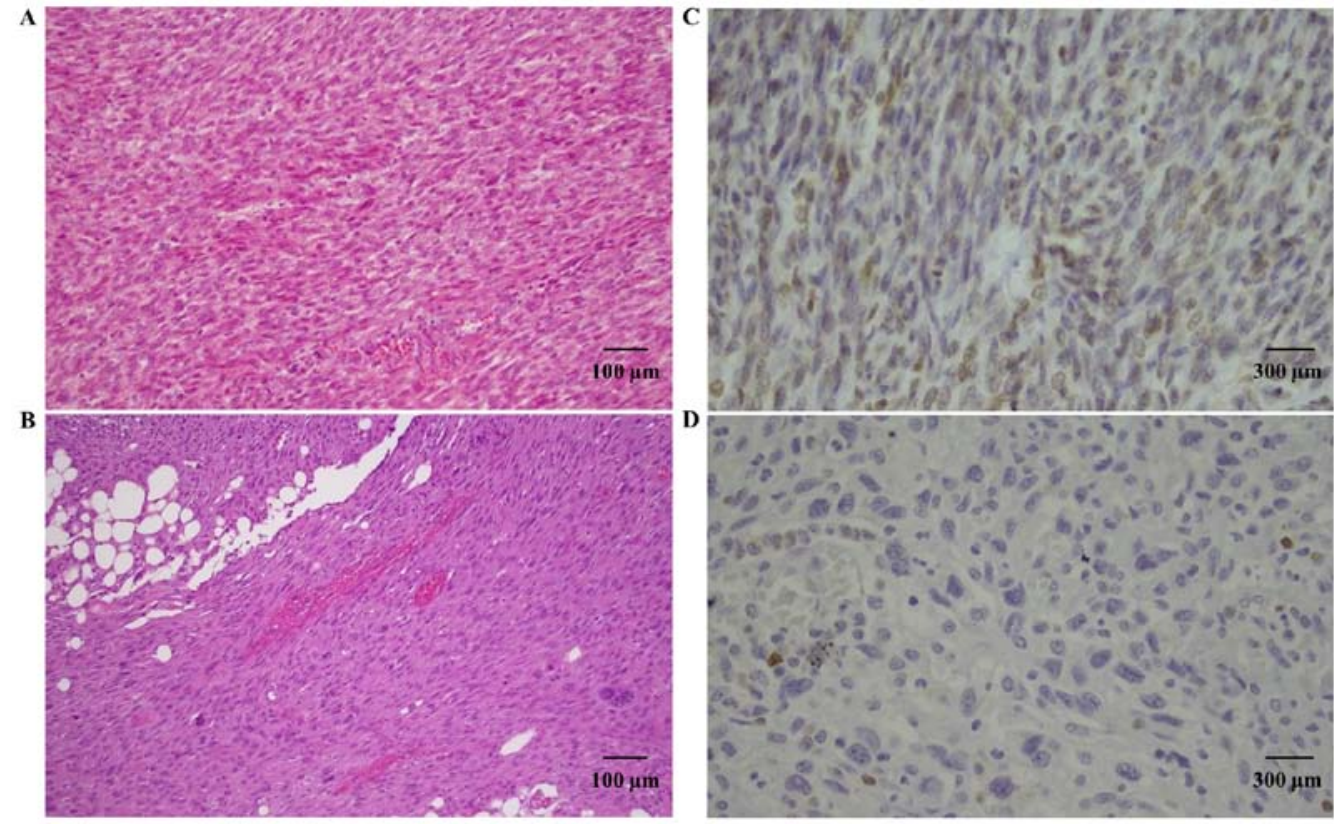

Figure 4. (A) Hematoxylin and eosin staining of a primitive STUMP. (B) Hematoxylin and eosin staining of a relapsed sarcoma. (C) Bcl-2 immunohistochemical staining of a primitive STUMP. (D) Bcl-2 immunohistochemical staining of a relapsed sarcoma. STUMP, smooth muscle tumors of uncertain malignant potential.

apoptotic cell death in a variety of cells, playing an important role in the growth of tumors. Notably, this amplification was not observed in sarcoma (Fig. 2B).

FISH results. To confirm the array-CGH results, FISH analysis was performed with an $I G H / B C L 2$ translocation probe. Multiple copies of the $B C L 2$ gene in the primitive STUMP of case 1 were confirmed and $I G H$ appeared disomic (Fig. 3A and C).

FISH on the undifferentiated sarcoma showed multiple copies of both BCL2 and IGH signals (Fig. 3B and D) and the analysis was extended using a probe for centromere 18 (Fig. 3E). Results revealed a signal distribution for centromere 18 that overlaps with the $B C L 2$ signal distribution, suggesting a polysomy of chromosome 18 that could explain the absence of amplification in array-CGH. FISH analysis performed on the relapsed cases 2 and 3 exhibited multiple copies of BCL2 (Fig. 3F and G).

A UroVysion test was also performed on the STUMP of case 1 in order to evaluate a possible polyploidy that could not be seen by array-CGH technique. Results showed $92 \%$ of the cells with chromosome 3 polysomy (ranging from 3 to 12 copies), 52 and $48 \%$ of the cells with chromosome 7 and 17 polysomy respectively (Fig. $3 \mathrm{H}$ ), supporting the hypothesis of a polyploid genome.

Immunohistochemistry results. The histological diagnosis and the immunohistochemical results are reported in Table II. As 
A

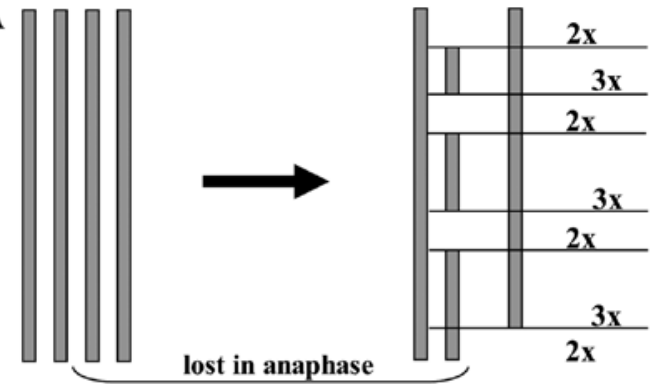

$1^{\circ}$ step - doubling chromosomal diploidy

$2^{\circ}$ step - chromosome anaphase lagging

$3^{\circ}$ step - fragmentations/deletions

(chromotripsis)

after array-CGH only gains and no

losses were evidenced

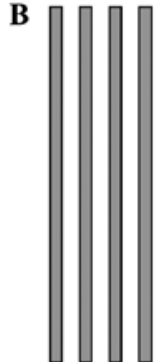

C

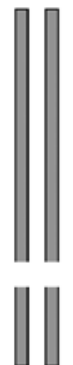

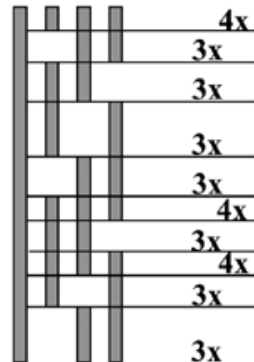

$1^{\circ}$ step - doubling chromosomal diploidy

$2^{\circ}$ step - fragmentations/deletions

(chromotripsis)

after array-CGH only gains and no losses were evidenced expected, the sarcomas presented a major proliferative trend compared to the STUMP; in particular the unique case of a STUMP recurrence as undifferentiated sarcoma showed a marked difference in the levels of tested protein expression (for instance p53).

Bcl-2 staining was present in two primitive STUMPs and in two relapsed tumors (one STUMP and one LMS). In particular, case 1 showed positive Bcl-2 expression in the primitive tumor, that was not maintained in the relapsed tumor (Fig. 4). On the contrary, case 3 showed high expression of Bcl-2 in both tumors. For case 2, the primitive tumor was not available for study, but the relapsed STUMP showed Bcl-2 expression.

\section{Discussion}

Uterine smooth muscle tumors are the most common female genital tract neoplasms. They are classified into: leiomyomas, STUMPs and leiomyosarcomas (4). While leiomyosarcoma is a malignant tumor and has been studied at length, STUMP remains ambiguous and has many unresolved issues. For this reason, we performed a study on three cases of STUMP with different types of relapse.

To our knowledge the present study showed for the first time an array comparative genomic hybridization analysis of a primitive STUMP and its relapsed tumor.

Array-CGH data showed a high number of gains and a very low number of losses (especially in primitive STUMP). This may be explained by a chromosome endoreduplication followed by a random loss in anaphase and/or deletions/chromotripsis of chromosome pieces (Fig. 5). In this hypothesis, losses would be 'masked' from the initial chromosome endoreduplication and the few losses may be attibuted to early events that arose prior to endoreduplication. This hypothesis is supported by the presence of polysomy in chromosomes 3, 717 and 18 detected by FISH, as reported in our results. The two tumors shared eight CNAs containing many genes, some implicated in other types of cancer, but never before reported in STUMPs and leiomyosarcomas. For example, TFGBR3 is considered a tumor-suppressor gene, commonly lost in various types of cancers (5-7), but it was recently reported to have a dual role in bladder cancer, acting as both a tumor suppressor and as a tumor promoter (8). In our cases, TGFBR3 appeared to play a tumor-promoting role, but this postulation should be further confirmed using a larger number of samples.

Another shared gained region included COROIC, whose amplification has been reported in primary effusion lymphoma (9) and whose gene expression silencing seems to inhibit cancer cell proliferation, migration and invasion in lung squamous cell carcinoma (10).

$B C L 2$ is an anti-apoptotic gene, whose expression appears to play an important role in the growth of human carcinomas. The role of $B C L 2$ has been well characterized and amplification of this gene may result in blockage of apoptosis (11). For this reason we decided to evaluate its copy number in our samples. 
The STUMP presented a real amplification of the BCL2 gene in the array-CGH analysis, that was not observed in the sarcoma and which was detected in FISH as multiple copies of the gene. This disparity with the array-CGH data may be explained by the idiosyncracies of the two techniques and the different information provided by them, as already reported in our previous study (12).

Several studies have shown an inverse correlation between Bcl-2 expression and p53 expression in different human malignancies (13-16). Our results suggest that Bcl-2 expression was independent of p53 expression both in the primitive and in the relapsed tumors, as evident in Table II.

It was also reported that $\mathrm{Bcl}-2$ expression is linked to a good clinical outcome and a better prognosis in non-small cell lung carcinoma (15), colorectal cancer (16) and leiomyosarcomas (1). Despite the fact that the number of analyzed samples was limited, our data appear to be contrary to these other studies, because multiple copies of BCL2 or Bcl-2 expression were present in the two primitive STUMPs and two relapsed tumors in a total of five tumors analyzed. Bcl-2 expression was confirmed in IHC in four of the five tested samples and moreover two out of the three patients succumbed to the disease.

The Bcl-2 family of proteins regulates apoptosis by controlling mitochondrial permeability. Several of these proteins, both anti-apoptotic and pro-apoptotic, have C-terminal transmembrane domains that are inserted in the outer membrane of mitochondria (17). In particular, the anti-apoptotic proteins $\mathrm{Bcl}-2$ and $\mathrm{Bcl}-\mathrm{xL}$ inhibit cytochrome $c$ release and therefore the activation of the apoptotic pathway.

For this reason copy number gain of BCL2 appears notably also as a therapeutic target. Strategies for inhibition of the Bcl-2 family of proteins currently in clinical trials essentially include: i) the use of antisense-based mechanisms to knock down Bcl-2 or Bcl-xL expression, or ii) the use of synthetic BH3 mimetic molecules (e.g., obatoclax, AT-101 and ABT-737) (18). Furthermore, it has recently been reported that Bcl-2 inhibition by siRNA might is useful for therapy in association with chemotherapeutic agents in MCF-7 breast cancer cells (19).

Despite the limited number of analyzed samples, BCL2 could be evaluated as a potential marker of malignancy and recurrence in STUMPs, however, this ambitious hypothesis must be confirmed using a larger number of patient samples.

\section{References}

1. Zhai YL, Nikaido T, Toki T, Shiozawa A, Orii A and Fujii S: Prognostic significance of bcl-2 expression in leiomyosarcoma of the uterus. Br J Cancer 80: 1658-1664, 1999.

2. Kotsopoulos IC, Barbetakis N, Asteriou C and Voutsas MG: Uterine smooth muscle tumor of uncertain malignant potential: A rare cause of multiple pulmonary nodules. Indian $\mathbf{J}$ Med Paediatr Oncol 33: 176-178, 2012.

3. Ip PP, Cheung AN and Clement PB: Uterine smooth muscle tumors of uncertain malignant potential (STUMP): A clinicopathologic analysis of 16 cases. Am J Surg Pathol 33: 992-1005, 2009.

4. Hewedi IH, Radwan NA and Shash LS: Diagnostic value of progesterone receptor and p53 expression in uterine smooth muscle tumors. Diagn Pathol 7: 1, 2012.

5. Copland JA, Luxon BA, Ajani L, Maity T, Campagnaro E, Guo H, LeGrand SN, Tamboli P and Wood CG: Genomic profiling identifies alterations in TGF $\beta$ signaling through loss of TGF $\beta$ receptor expression in human renal cell carcinogenesis and progression. Oncogene 22: 8053-8062, 2003.
6. Dong M, How T, Kirkbride KC, Gordon KJ, Lee JD, Hempel N, Kelly P, Moeller BJ, Marks JR and Blobe GC: The type III TGF- $\beta$ receptor suppresses breast cancer progression. J Clin Invest 117: 206-217, 2007

7. Turley RS, Finger EC, Hempel N, How T, Fields TA and Blobe GC: The type III transforming growth factor- $\beta$ receptor as a novel tumor suppressor gene in prostate cancer. Cancer Res 67: 1090-1098, 2007.

8. Liu XL, Xiao K, Xue B, Yang D, Lei Z, Shan Y and Zhang HT: Dual role of TGFBR3 in bladder cancer. Oncol Rep 30: 1301-1308, 2013.

9. Luan SL, Boulanger E, Ye H, Chanudet E, Johnson N, Hamoudi RA, Bacon CM, Liu H, Huang Y, Said J, et al: Primary effusion lymphoma: Genomic profiling revealed amplification of SELPLG and CORO1C encoding for proteins important for cell migration. J Pathol 222: 166-179, 2010.

10. Mataki H, Enokida H, Chiyomaru T, Mizuno K, Matsushita R, Goto Y, Nishikawa R, Higashimoto I, Samukawa T, Nakagawa M, et al: Downregulation of the microRNA-1/133a cluster enhances cancer cell migration and invasion in lungsquamous cell carcinoma via regulation of Coronin1C. J Hum Genet 60: 53-61, 2015 .

11. Petrini I, Meltzer PS, Zucali PA, Luo J, Lee C, Santoro A, Lee HS, Killian KJ, Wang Y, Tsokos M, et al: Copy number aberrations of $B C L 2$ and $C D K N 2 A / B$ identified by array-CGH in thymic epithelial tumors. Cell Death Dis 3: e351, 2012.

12. Panzeri E, Conconi D, Antolini L, Redaelli S, Valsecchi MG, Bovo G, Pallotti F, Viganò $\mathrm{P}$, Strada $\mathrm{G}$, Dalprà L, et al: Chromosomal aberrations in bladder cancer: Fresh versus formalin fixed paraffin embedded tissue and targeted FISH versus wide microarray-based $\mathrm{CGH}$ analysis. PLoS One 6: e24237, 2011

13. Silvestrini R, Veneroni S, Daidone MG, Benini E, Boracchi $\mathrm{P}$ Mezzetti M, Di Fronzo G, Rilke F and Veronesi U: The Bcl-2 protein: A prognostic indicator strongly related to $\mathrm{p} 53$ protein in lymph node-negative breast cancer patients. J Natl Cancer Inst 86: 499-504, 1994.

14. Alderson LM, Castleberg RL, Harsh GR IV, Louis DN and Henson JW: Human gliomas with wild-type p53 express bcl-2. Cancer Res 55: 999-1001, 1995.

15. Fontanini G, Vignati S, Bigini D, Mussi A, Lucchi M, Angeletti CA, Basolo $\mathrm{F}$ and Bevilacqua $\mathrm{G}$ : Bcl-2 protein: A prognostic factor inversely correlated to p53 in non-small-cell lung cancer. Br J Cancer 71: 1003-1007, 1995.

16. Kaklamanis L, Savage A, Whitehouse R, DoussisAnagnostopoulou I, Biddolph S, Tsiotos P, Mortensen N, Gatter KC and Harris AL: Bcl-2 protein expression: Association with p53 and prognosis in colorectal cancer. Br J Cancer 77: 1864-1869, 1998

17. Yip KW and Reed JC: Bcl-2 family proteins and cancer. Oncogene 27: 6398-6406, 2008.

18. Scarfò L and Ghia P: Reprogramming cell death: BCL2 family inhibition in hematological malignancies. Immunol Lett 155: 36-39, 2013

19. Talaiezadeh A, Jalali F, Galehdari H and Khodadadi A: Time depended Bcl-2 inhibition might be useful for a targeted drug therapy. Cancer Cell Int 15: 105, 2015.

20. Fischer H, Stenling R, Rubio C and Lindblom A: Colorectal carcinogenesis is associated with stromal expression of COL11Al and COL5A2. Carcinogenesis 22: 875-878, 2001.

21. Wang LH, Xiang J, Yan M, Zhang Y, Zhao Y, Yue CF, Xu J, Zheng FM, Chen JN, Kang Z, et al: The mitotic kinase Aurora-A induces mammary cell migration and breast cancer metastasis by activating the Cofilin-F-actin pathway. Cancer Res 70: 9118-9128, 2010 .

22. Stadler ZK, Esposito D, Shah S, Vijai J, Yamrom B, Levy D, Lee YH, Kendall J, Leotta A, Ronemus M, et al: Rare de novo germline copy-number variation in testicular cancer. Am J Hum Genet 91: 379-383, 2012.

23. Mudduluru G, Vajkoczy P and Allgayer H: Myeloid zinc finger 1 induces migration, invasion, and in vivo metastasis through Axl gene expression in solid cancer. Mol Cancer Res 8: 159-169, 2010. 